Article

\title{
Bullying and Cyberbullying in Adolescents from Disadvantaged Areas: Validation of Questionnaires; Prevalence Rates; and Relationship to Self-Esteem, Empathy and Social Skills
}

\author{
Jacinto Martínez ${ }^{1}$, Antonio J. Rodríguez-Hidalgo ${ }^{2, *} \mathbb{C}$ and Izabela Zych ${ }^{1}$ \\ 1 Department of Psychology, University of Cordoba, Avda. San Alberto Magno S/N, 14071 Córdoba, Spain; \\ jacintomasa@gmail.com (J.M.); izych@uco.es (I.Z.) \\ 2 Department of Psychology, Cátedra de Cooperación al Desarrollo, University of Cordoba, \\ Avda. San Alberto Magno S/N, 14071 Córdoba, Spain \\ * Correspondence: ajrodriguez@uco.es; Tel.: +34-957-212-077; Fax: +34-957-212-513
}

Received: 18 June 2020; Accepted: 19 August 2020; Published: 26 August 2020

check for updates

\begin{abstract}
Although bullying and cyberbullying have been widely studied in diverse geographical areas, the number of studies in isolated regions, located in rainforests such as the Peruvian Amazonia, is low. Most research has been conducted in wealthy, Western countries, although disadvantaged areas are usually the most affected by various problems. Thus, the aims of this study were to validate bullying and cyberbullying measurement instruments among adolescents in the Peruvian Amazonia, to determine the prevalence rates of bullying and cyberbullying among this population, and to examine how bullying and cyberbullying relate to self-esteem, empathy, and social skills. The sample included 607 students from the region of Loreto (Peruvian Amazonia) who completed self-report questionnaires. Both questionnaires used in the sample were found to have good psychometric properties. Results showed that bullying and cyberbullying are prevalent among teenagers in the Amazonia. Low self-esteem and high affective empathy predicted bullying victimization. Being a bully was related to high assertiveness. Being a bully-victim was related to low self-esteem and low assertiveness. Cybervictims showed higher cognitive empathy. Cyberbullies showed higher affective empathy in comparison to uninvolved adolescents. Having low self-esteem and higher affective empathy were related to being a cyberbully/victim. This study provides a validated questionnaire that can be used for research and practice in the Amazonia. Based on the current results, tailored anti-bullying and anti-cyberbullying interventions with components focused on self-esteem, empathy, and social skills should be implemented in Peruvian secondary schools.
\end{abstract}

Keywords: bullying; cyberbullying; self-esteem; empathy; social skills

\section{Introduction}

Bullying and cyberbullying have been studied for over four decades. However, a systematic review showed that, up to the year 2015, more than $75 \%$ of bullying studies had been conducted in Europe and the United States [1]. Although describing, understanding, and reducing violence-including bullying-is necessary worldwide, it is especially important in disadvantaged geographical regions [2,3]. Hence, the current study focuses on bullying and cyberbullying in the Peruvian Amazonia, an area which, to our knowledge, has not yet been studied in relation to bullying and cyberbullying.

Bullying is defined as repeated, long-term behavior involving certain students intentionally acting aggressively towards peers who cannot defend themselves easily [4]. Bullying is based on a dominance-submission relationship [5] that allows the perpetrator to avoid punishment and makes 
the victim more vulnerable, and frequently unable to escape from this situation [6]. Bullying is a complex psychosocial group behavior that includes different roles [7]. Victims are the students who are repeatedly abused, and bullies are the students who perpetrate aggressive behaviors towards their peers. Bully-victims are the students who are bullied and bully others at the same time, and there are also bystanders who reinforce the perpetrator's behavior.

The growth of technology brings many opportunities, but it also provides a context for a new form of bullying, called cyberbullying. Cyberbullying shares many characteristics with face-to-face bullying, such as being intentionally harmful, being repetitive, and involving a power imbalance. However, cyberbullying is perpetrated via electronic devices, can take place $24 \mathrm{~h}$ a day, 7 days a week, allows perpetrators to remain anonymous, and is more likely to have a bigger audience [8,9]. Cyberbullying does not require the perpetrator to repeat their violent actions, as one or two cyberaggressions can remain online for long periods of time [10], thus lengthening the victim's suffering [11].

Bullying and cyberbullying have serious short-, medium-, and long-term consequences [1]. Moreover, they are related to other antisocial behaviors, according to both longitudinal and cross-sectional studies [12]. Reducing violence and other antisocial behaviors in minors has become one of the top scientific, political, and practical priorities in social sciences. However, only $10 \%$ of studies with a focus on different types of violence have been conducted in low- and middle-income countries, even though $85 \%$ of violent deaths occur in low- and middle-income countries [13]. The number of studies on bullying and cyberbullying in disadvantaged areas is also low [14] and, at the same time, understanding the subject is the key to reducing violence globally. For these reasons, it is necessary to validate instruments, to examine bullying and cyberbullying in disadvantaged regions, and to uncover possible risk and protective factors.

A review on bullying and cyberbullying research in Latin America [15] showed that there are still many gaps in knowledge in that geographical area. Regarding cyberbullying, the number of studies conducted in Latin America is still low, and a small percentage of them are published in high-impact journals. Regarding both bullying and cyberbullying, several high-impact articles about the validation of questionnaires in countries such as Colombia [16,17] and Ecuador [3] have been recently published. Latin America, however, is a large, socioeconomically diverse, and culturally diverse geographical area, and it is necessary to validate instruments in its different countries and regions.

\subsection{Prevalence Rates of Bullying and Cyberbullying: Research in Disadvantaged Areas}

A global study with 104,614 students from 19 countries showed that $34 \%$ of the respondents reported bullying victimization [18]. Other international studies reported that approximately one out of three minors was involved in bullying and one out of five was involved in cyberbullying [1,19]. Another review of cyberbullying research has shown that $56.9 \%$ of survey respondents had been victimized in the last 6 months and $65 \%$ had been victimized at least once during their lifetime [20]. A cross-European study found overall cyberperpetration prevalence rates of $17.7 \%$ in males and $10.9 \%$ in females, and overall cybervictimization rates of $16.5 \%$ in males and $16.4 \%$ in females [21].

Research has shown that there is more violence in schools in Latin America than in Europe or the United States [22]. A review that analyzed prevalence rates of bullying across 234 Latin American articles found the average prevalence rate of bullying was $29.31 \%$ and the average prevalence rate of cyberbullying was between $2.5 \%$ and $42.5 \%$ [15]. A Latin American study conducted by The United Nations Children's Fund (UNICEF) found that between $50 \%$ and $70 \%$ of students were involved in bullying [23]. With respect to cyberbullying, a study conducted in 16 Latin American countries reported prevalence rates between 13\% and 63\% [24]. A more recent study by Cabra and Marciales [25] concluded that there is still little information about bullying and cyberbullying in Latin America, and, therefore, no conclusion regarding overall prevalence rates can be drawn. Moreover, most studies in Latin America included students from Brazil, Colombia, Chile, and Mexico [15]. Therefore, it is still necessary to conduct research on bullying and cyberbullying in different Latin American regions, especially in disadvantaged areas. 
Peruvian Amazonia is one of the regions where research on bullying and cyberbullying is still needed. The Peruvian Ministry of Health [26] reported that 38\% of Peruvian students had been physically attacked in the previous year and that $47.5 \%$ had been victims of bullying in the previous month. According to the Peruvian anti-bullying platform SiseVe (https://siseve.pe), from 2013 to 2018, a total of 22,126 cases of school violence were reported, with $55 \%$ of them considered bullying [27]. The National Peruvian Survey on Social Relationships [28], conducted in 2015, showed that $73.5 \%$ of children and $73.8 \%$ of adolescents had suffered some type of violence during their school years. Another study, with teenagers between 12 and 17 years of age, revealed that $47 \%$ of them had been victims of violence perpetrated by peers in the past year [29]. As for cyberbullying in Peru, victimization prevalence rates of $31.3 \%$ were found [30], while other studies showed a $24.6 \%$ prevalence rate [31]. Another study, with almost one thousand Peruvian students between 9 and 11 years of age, found that between $0.7 \%$ and $3.2 \%$ of them had occasionally witnessed cyberbullying [32].

Thus, several studies have revealed that bullying and cyberbullying do exist in Peru, although prevalence rates vary across studies. Even though some preliminary results about bullying and cyberbullying in Peru have been published, to our knowledge, there are still no validated questionnaires to measure bullying and cyberbullying in Peru. Validated questionnaires are indispensable for collecting data with scientific rigor. Moreover, a review of scientific literature shows that there are no projects with samples coming from particularly disadvantaged areas, such as the Peruvian Amazonia.

\subsection{Bullying and Cyberbullying: Relation to Self-Esteem, Empathy, and Social Skills}

Several studies have revealed that self-esteem is related to bullying and cyberbullying. A recent meta-analysis found that peer violence predicted low self-esteem, and that low self-esteem predicted more peer violence [33]. A literature review performed by Kowalski [34] concluded that low self-esteem is a risk factor for cybervictimization, and that high self-esteem can be a protective factor against it. The relation between low self-esteem and victimization might be explained by the fact that perpetrators look for victims who are less capable of defending themselves [35].

Other studies have shown that low self-esteem is related to aggression [36]. A systematic review of meta-analyses on the protective factors against bullying and cyberbullying discovered that high self-esteem protects against involvement in different bullying and cyberbullying roles [37]. Another meta-analysis [38] found that high self-esteem was related to decreased bullying victimization and perpetration. Meta-analyses conducted by Chen et al. and Kowalski et al. $[39,40]$ found relations between high self-esteem and decreased victimization, and perpetration of cyberbullying. Other studies found that low self-esteem was related to self-victimization and ethnic-cultural victimization [41].

Scientific results regarding the relations between empathy, bullying, and cyberbullying are inconclusive. In general, high empathy has been described as a protective factor against bullying [37,42], while low empathy has been described as a risk factor for bullying [37,43-45]. However, some studies have found low levels of empathy in bullies and high levels of empathy in victims $[37,46]$. A meta-analysis found low empathy in cyberbullies and high affective empathy in cybervictims [37]. High affective empathy in cybervictims was also found in previous research [47]. There are also studies that did not find a significant relation between empathy, bullying, and cyberbullying [37,40].

These inconsistent results have been explained in several different ways. On the one hand, it has been suggested that people with high levels of empathy can better understand the victim's feelings, which prevents them from being abusive [48]. Given that high affective empathy has been related to victimization [49], it is possible that victims are more sensitive because they suffered more than the uninvolved students. Regarding bullies, it is also possible that they do understand and even share others' feelings but continue to harm victims as their character may be Machiavellian and manipulative [50].

In addition to self-esteem and empathy, social skills have also been studied in relation to bullying and cyberbullying. Social skills are described as an essential tool for proper adolescent development, social adjustment, and social relationships [51]. Some studies have found a relationship 
between low social skills and involvement in bullying [52-55]. Additionally, different social and emotional competencies were found to be protective against bullying and cyberbullying [37]. Various meta-analyses have shown that social competencies, together with conflict resolution skills, relate to lower victimization $[40,56]$, and other studies have found that social skills are protective against the possibility of becoming bullies and bully-victims [56]. Scientific literature has shown that an increase in different social skills, particularly conflict resolution, is related to a decrease in bullying [57]. More assertiveness is related to less aggression and to defending the victims of bullying [58]. It has also been found that low social abilities predict more bullying [59] and peer victimization [60].

Reviews of the scientific literature on the relations between self-esteem, empathy, social skills, and violence (including bullying and cyberbullying) show that there is an emerging research line focused on bullying and cyberbullying in disadvantaged areas. A study in Ecuador found that low self-esteem, as well as high levels of affective and cognitive empathy, predicted high levels of bullying victimization [3]. However, victimization was not predicted by social skills. They also found that bullying perpetration was predicted by low self-esteem and low cognitive empathy. Social skills did not predict bullying. Nevertheless, it is necessary to advance knowledge in the field over different disadvantaged geographical areas, and to design effective intervention and prevention programs.

\subsection{Current Study}

Reviews of the scientific literature found that bullying and cyberbullying are present and prevalent in different countries. Several studies showed relations between bullying, cyberbullying, empathy, self-esteem, and social skills. However, it is remarkable that the number of studies in Latin America is lower than in Europe or in the United States. Moreover, bullying and cyberbullying have not yet been studied in many disadvantaged and isolated regions, such as the rainforest region. Although some studies have shown high prevalence rates of bullying and cyberbullying in disadvantaged areas, there are still no validated instruments to measure bullying and cyberbullying in most of these regions.

Empathy, social skills, and self-esteem are studied as possible protective factors against bullying and cyberbullying around the world. Thus, it is important to discover if they can also protect adolescents in disadvantaged areas from bullying. This is particularly important, because most violent acts are committed in regions where the number of studies about violence is extremely low.

Thus, this study aims to: 1. Validate the European Bullying Intervention Project Questionnaire and the European Cyberbullying Intervention Project Questionnaire [61] in Peruvian Amazonia; 2. Describe the prevalence rates of different bullying and cyberbullying roles in Peruvian Amazonia; and 3. Discover direct and unique relationships between self-esteem, empathy, and social skills, and the different bullying and cyberbullying roles. It is expected that the questionnaires have good psychometric properties; we also expected to find relatively high prevalence rates of bullying and cyberbullying; and a relationship between high self-esteem, empathy, and social skills, and low involvement in bullying and cyberbullying.

\section{Method}

\subsection{Participants}

The sample of this study consisted of 607 students from four different state schools in the city of Iquitos, region of Loreto (Peruvian Amazonia). Participants were between 12 and 19 years old (Mean age = 14.5, $\mathrm{SD}=1.69$ ), and were enrolled in one of the five grades of Compulsory Secondary Education in Peru.

The sample consisted of $51.7 \%$ males and $48.3 \%$ females. Out of these students, $22.1 \%$ were enrolled in Grade 1, 22.1\% in Grade 2, 17.3\% in Grade 3, 19.9\% in Grade 4, and 18.6\% in Grade 5. The sample was widely diverse; $73.5 \%$ of the students were from the majority ethnic-cultural group (mixed-ethnicity), 20.4\% were Caucasian, 5.9\% were Native American, and $0.2 \%$ were from other ethnic-cultural groups. 


\subsection{Instruments}

The first part of the questionnaire consisted of questions related to the different sociodemographic variables such as school, gender, age, grade, and ethnic-cultural group. The rest of the variables were measured with the following questionnaires.

Bullying was measured with the Spanish version of the European Bullying Intervention Project Questionnaire (EBIP-Q) [61,62]. The questionnaire has 14 items, seven of which refer to victimization (e.g., 'A classmate has punched me, kicked me or pushed me') and seven of which refer to perpetration (e.g., 'I punched, kicked or pushed a classmate'). The items were answered on a five-point Likert scale, ranging from 1 (no) to 5 (yes, more than once per week). In this study, questions referred to incidences occurring in the past two months. The reliability of the scale was good (victimization $\alpha=0.75, \Omega=0.75$ and perpetration $\alpha=0.75, \Omega=0.75$ ).

Cyberbullying was measured with the Spanish version of the European Cyberbullying Intervention Project Questionnaire (ECIP-Q) [61-63]. It has 22 items, divided into 11 items on cybervictimization (e.g., 'Somebody has said offensive words to me or has insulted me using their phone or the Internet') and 11 items on cyberperpetration (e.g., "I have isolated or ignored somebody on social media or chats"). The items were answered on a five-point Likert scale, ranging from 1 (no) to 5 (yes, more than once per week), and referred to incidences occurring in the past two months. The questionnaire had a good reliability (cybervictimization $\alpha=0.86, \Omega=0.86$ and cyberperpetration $\alpha=0.92, \Omega=0.92$ ).

Self-esteem was measured using Rosenberg's Self-Esteem Scale (RSES). It was created by Rosenberg (1989) and later validated in Spain with a sample of adolescents [64]. The scale consists of10 items focused on different aspects of self-esteem (e.g., 'In general, I am satisfied with myself'). It is answered on a four-point Likert scale, ranging from 1 (completely disagree) to 4 (completely agree), with acceptable reliability $(\alpha=0.67, \Omega=0.68)$.

Empathy was measured with the Spanish version of the Basic Empathy Scale [44], adapted and reduced [51]. It has two scales: affective empathy (e.g., 'After being with a friend who is sad about something, I usually feel sad') and cognitive empathy (e.g., 'When someone is feeling 'down', I can usually understand how s/he feels'). The first scale contains four items, and the second scale contains five items. Items are answered on a five-point Likert like scale, ranging from 1 (completely disagree) to 5 (completely agree). The scale has good reliability ( $\alpha$ and $\Omega$ affective empathy $=0.77$ and $\alpha$ and $\Omega$ cognitive empathy $=0.84)$.

Social skills were measured with the Social Skills Evaluation Scale [51], which consists of 12 items answered on a seven-point Likert scale, ranging from 1 (completely false) to 7 (completely true). Some of them are affirmative questions, while others are negative questions. Items are divided into three scales: communicative or relationship skills with five items (e.g., 'I struggle to start a conversation with a stranger'), assertiveness with three items (e.g., 'I usually praise and congratulate my peers when they do something right'), and conflict resolution skills with four items (e.g., 'When two friends have an argument, they usually come to me for help'). These subscales had acceptable reliability $(\alpha$ and $\Omega$ communicative skills $=0.78, \alpha$ and $\Omega$ assertiveness $=0.66$, and $\alpha$ and $\Omega$ conflict resolution $=0.69$ ).

\subsection{Procedure}

The study was conducted as a part of a cooperation for development project, including the University of Cordoba (Spain) and La Restinga Association (Peru). Within this project, Loreto's Regional Education Department was contacted, and data were collected as a part of the current agreement between these institutions. First, a group of psychologists from La Restringa Association revised the questionnaires to find possible linguistic differences between its original version validated in Spain and expressions used in the Peruvian Amazonia. Several terms were changed (i.e., "piratear" was substituted with "hackear", and "ordenador" was substituted with "computadora"). Then, six school directors were contacted and asked for cooperation, and four agreed to participate. Once the study was approved by each school, one class from each grade was randomly selected to fill in the survey. Parents were informed about the study and had the right to decline to participate. Participants 
were included if they were in any grade (1 to 6) of secondary education, had parental consent, and agreed to participate. Participants were excluded if they did not have parental consent or if they declined to participate in the study.

Participants received detailed instructions on how to fill in the questionnaires. After obtaining participants' consent to take part in the study, data were collected anonymously and voluntarily, under the supervision of a researcher. Participants had the right to withdraw from the study at any time. No personal information that could identify the participants was collected. National and international research ethics regulations, including the Declaration of Helsinki and the Personal Data Protection Law, were followed. Procedure was approved by the Ethics Committee of the University of Cordoba, Spain (PSI2016-74871-R).

\subsection{Data Analyses}

In order to analyze the psychometric properties of the European Bullying Intervention Project Questionnaire, and the European Cyberbullying Intervention Project Questionnaire, Confirmatory Factor Analyses were conducted with the original factor structure of the questionnaires. To check if the data collected in this study fit the original factor structure, analyses were conducted with the EQS 6.2 software (Multivariate Software, Inc., Encino, CA, USA) [65]. The estimation methods were the robust maximum likelihood method and polychoric correlations, given the ordinal scales of the variables. Model fit was tested through different indices such as comparative fit index (CFI), normed-fit index (NFI), and non-normed fit index (NNFI), bigger than 0.90 , and root mean square error of approximation (RMSEA) below 0.08 [66].

Reliability was estimated with the FACTOR 10 (Universitat Rovira i Virgili, Tarragona, Spain) [67] software. Reliability coefficients included Cronbach's alpha and McDonald's omega, both calculated using the polychoric correlations matrix.

Prevalence rates of involvement in different bullying and cyberbullying roles were analyzed with PASW-Statistics 20 (IBM, Armonk, NY, USA) [68]. Students were classified into different bullying and cyberbullying roles based on their responses to the items focusing on victimization and perpetration. Participants who responded never, once, or twice to all the items on perpetration and victimization were considered uninvolved. Participants who responded once or twice per month or more to any item on aggression, and responded never, once, or twice to all items on victimization, were considered bullies (and vice versa for the victims). Participants who responded once or twice per month or more to any item on both perpetration and victimization were considered bully-victims.

Descriptive analyses were performed to discover prevalence rates of different bullying and cyberbullying roles. Direct relations among variables were analyzed with Pearson's correlations. Unique relations between predictors (self-esteem, empathy, and social skills) and different bullying and cyberbullying roles were analyzed with multinomial logistic regression analysis.

\section{Results}

Results of the Confirmatory Factor Analyses showed that both instruments had good psychometric properties. Factor loadings and model fit indices were adequate. Details are specified in Figures 1 and 2. 


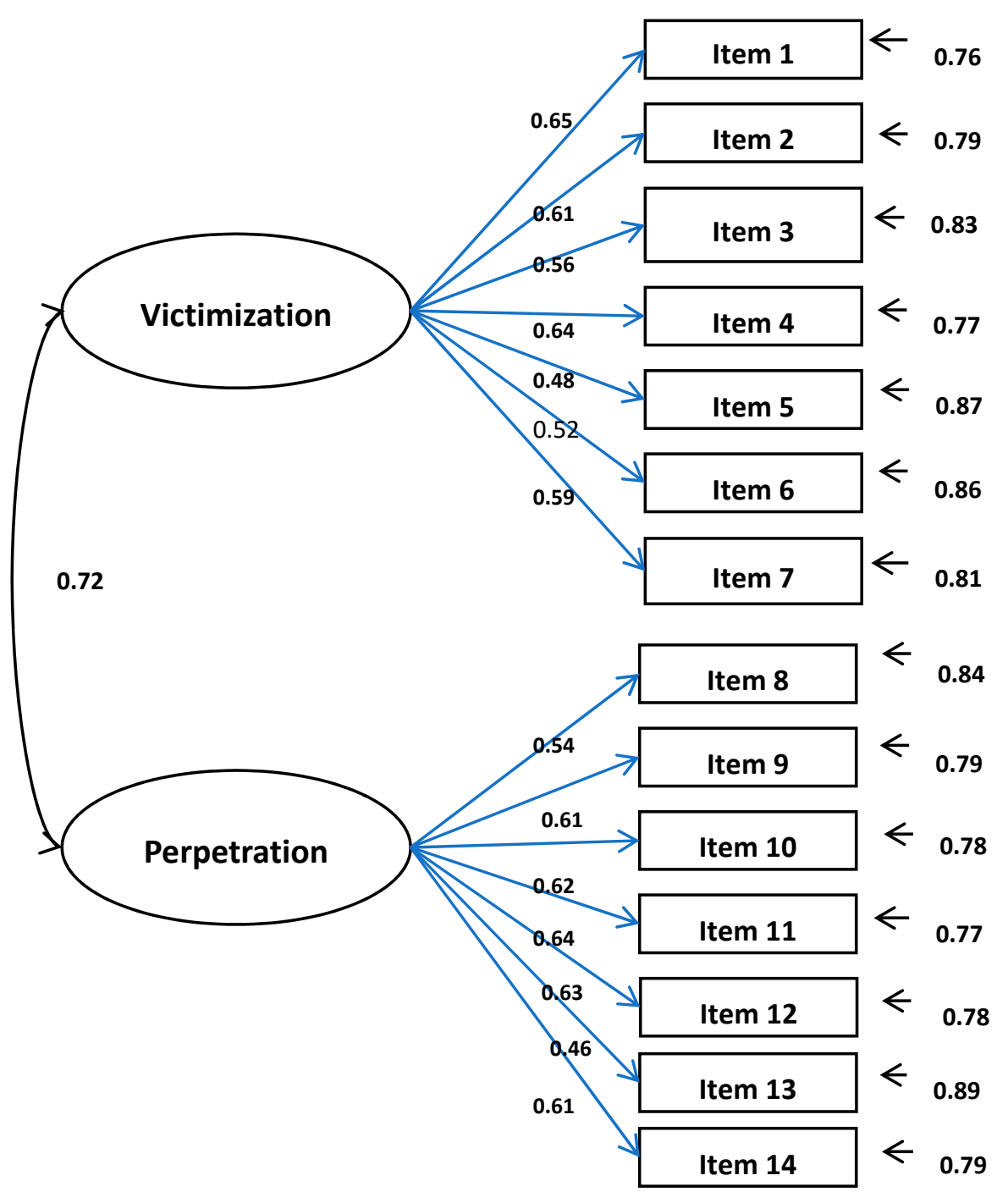

$\mathrm{S} / \mathrm{B}$ chi-square $=225.04, \mathrm{df}=76, \mathrm{CFI}=0.94, \mathrm{NFI}=0.91, \mathrm{NNFI}=0.93, \mathrm{RMSEA}=0.058(90 \% \mathrm{CI}=0.049-0.067)$.

Figure 1. Confirmatory Factor Analyses of the European Bullying Intervention Project Questionnaire. 


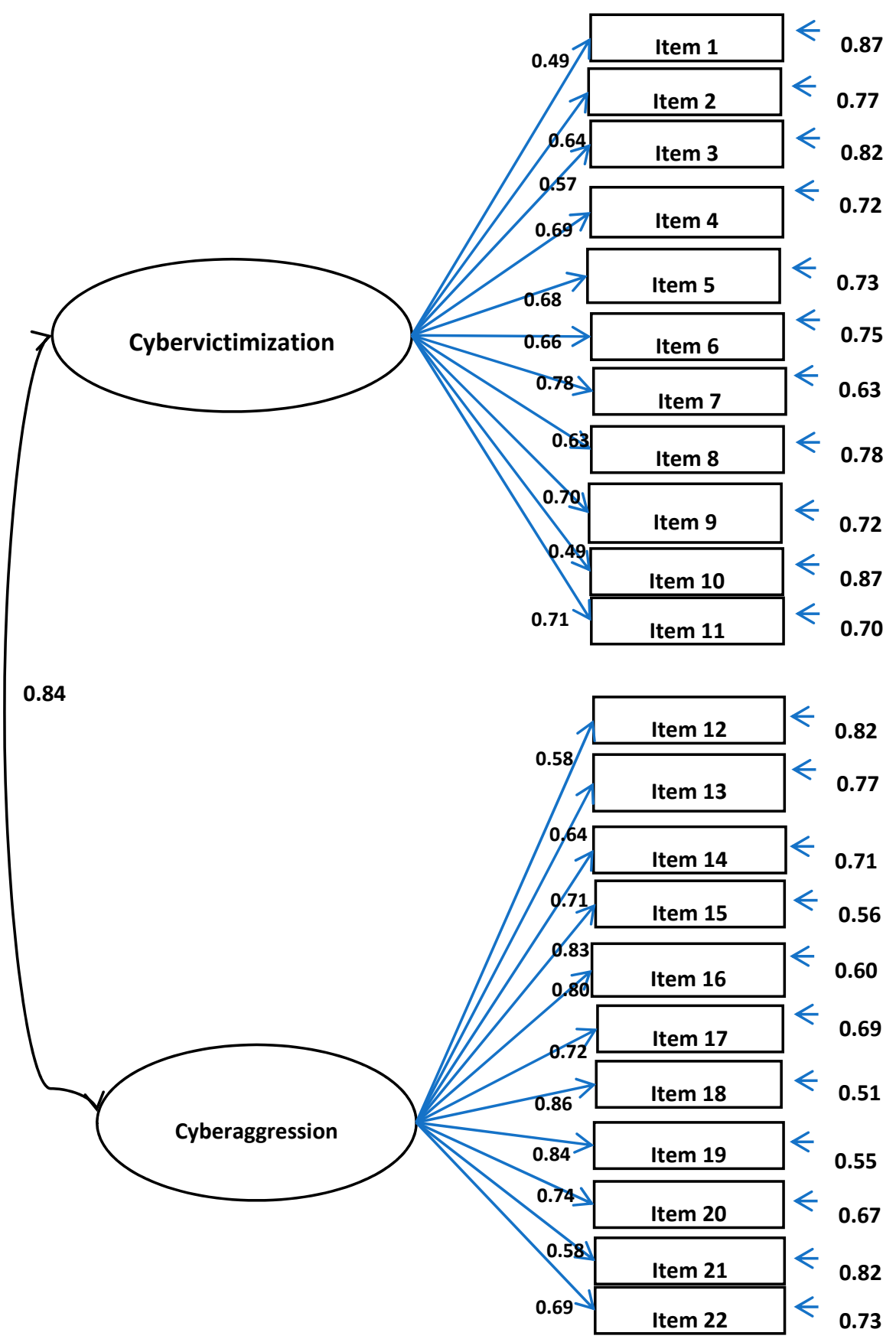

$\mathrm{S} / \mathrm{B}$ chi-square $=583.28, \mathrm{df}=208, \mathrm{CFI}=0.95, \mathrm{NFI}, 0.95, \mathrm{NNFI}=0.96, \mathrm{RMSEA}=0.058(90 \% \mathrm{CI}=0.052-0.064)$

Figure 2. Confirmatory Factor Analyses of the European Cyberbullying Intervention Project Questionnaire.

The percentages of students involved in each bullying and cyberbullying role are shown in Figure 3. As can be seen in Figure 3, there are more participants involved in bullying than in cyberbullying. In both phenomena, bully-victim is the most common role. 


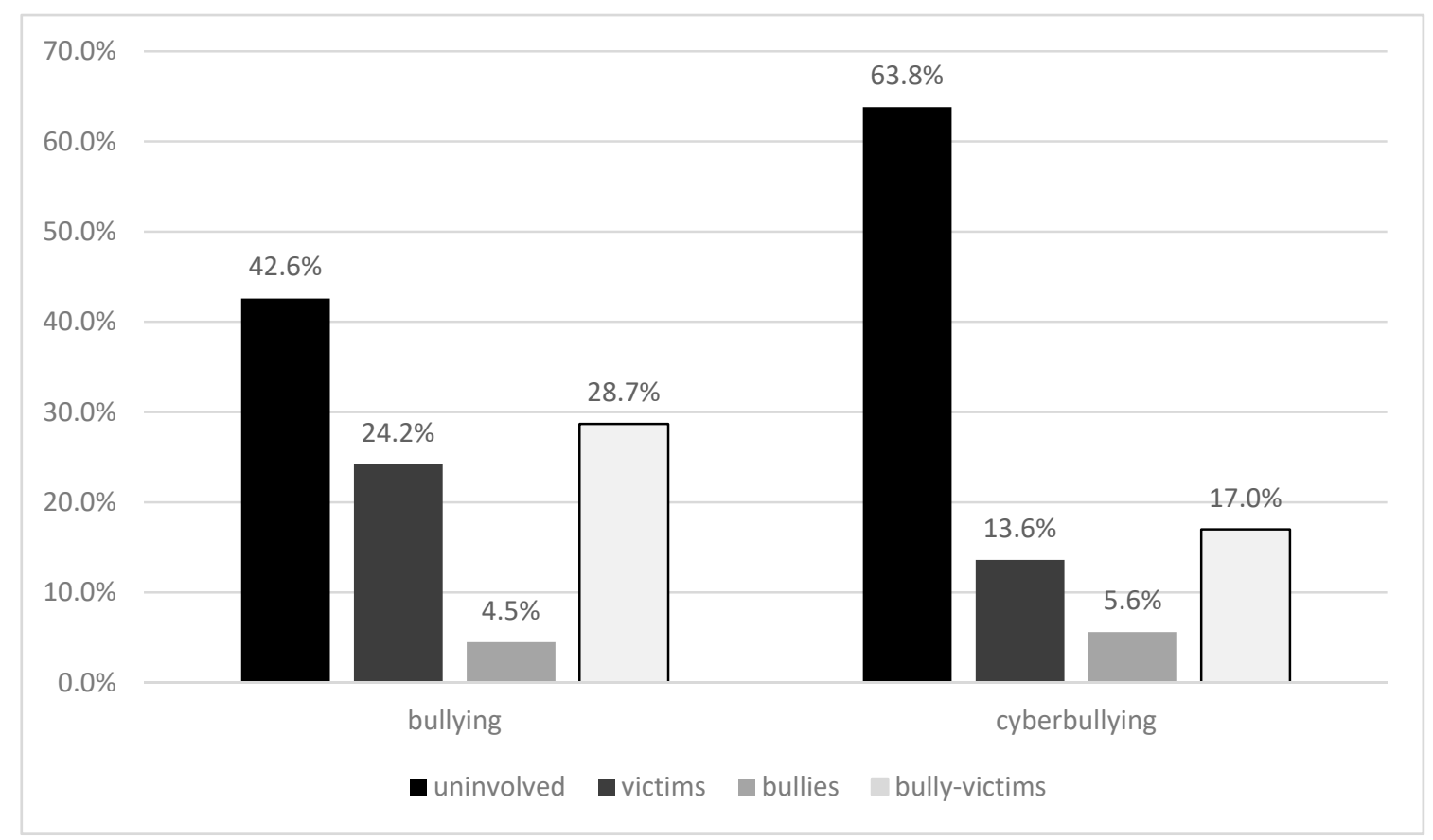

Figure 3. Prevalence rates of involvement in different bullying and cyberbullying roles.

Regarding the overlap between the bullying and cyberbullying roles, Table 1 shows that only $36.7 \%$ of students were not involved in any bullying or cyberbullying role.

Table 1. Prevalence rates taking into account the overlap among bullying and cyberbullying roles.

\begin{tabular}{ccccc}
\hline Roles & Uninvolved in Cyberbullying & Cybervictim & Cyberbully & Cyberbully/Victim \\
\hline Uninvolved in & $36.7 \%$ & $3.1 \%$ & $1.2 \%$ & $1.7 \%$ \\
bullying & $15.5 \%$ & $5.2 \%$ & $0.8 \%$ & $3.3 \%$ \\
Victim & $2.3 \%$ & $1 \%$ & $0.8 \%$ & $0.4 \%$ \\
Bully & $9.9 \%$ & $4.3 \%$ & $2.5 \%$ & $11.3 \%$ \\
Bully-victim & $C$ & & \\
\hline
\end{tabular}

Chi-square ${ }_{(9)}=133.17, p<0.01, \mathrm{~V}=0.28, p<0.01$.

Table 2 shows Pearson's correlations among the study variables. Positive significant correlations were found between victimization and perpetration in both bullying and cyberbullying. Victimization and perpetration of cyberbullying were both related to low self-esteem. Only victimization of bullying, but not perpetration, was related to low self-esteem. Victimization (but not perpetration) of both bullying and cyberbullying were related to high affective and cognitive empathy. Bullying and cyberbullying perpetration were related to low assertiveness. There were no other significant relations between bullying, cyberbullying, and social skills. 
Table 2. Correlations among the study variables.

\begin{tabular}{|c|c|c|c|c|c|c|c|c|c|}
\hline Study Variables & 1 & 2 & 3 & 4 & 5 & 6 & 7 & 8 & 9 \\
\hline 1. Victimization & 1 & & & & & & & & \\
\hline 2. Bullying perpetration & $398 * *$ & 1 & & & & & & & \\
\hline 4. Cyberperpetration & $0.347^{* *}$ & $0.471^{* *}$ & $0.603 * *$ & 1 & & & & & \\
\hline 5. Self-esteem & $-215 * *$ & -0.083 & $-0.152^{* *}$ & $-0.111 *$ & 1 & & & & \\
\hline 6. Affective empathy & $0.205^{* *}$ & 0.012 & $0.165^{* *}$ & 0.071 & 0.005 & 1 & & & \\
\hline 9. Assertiveness & -0.041 & $-0.111^{* *}$ & 0.004 & $-0.117 * *$ & $0.217^{* *}$ & $0.348^{* *}$ & $0.437^{* *}$ & $0.307^{* *}$ & 1 \\
\hline 10. Conflict resolution & -0.001 & -0.057 & 0.038 & -0.049 & $0.171 * *$ & $0.389 * *$ & $0.395 * *$ & $0.270 * *$ & $0.612 * *$ \\
\hline
\end{tabular}

Table 3 shows the results of the multinomial regression analysis, with bullying roles as dependent variables and self-esteem, empathy, and social skills as predictors (Nagelkerke $\mathrm{R}^{2}=0.19$ ). Low self-esteem and high affective empathy uniquely predicted victimization. Being a bully was uniquely related to high assertiveness. Being a bully-victim was uniquely related to being older, male, having low self-esteem, and having low assertiveness.

Table 3. Multinomial regression with age, gender, self-esteem, empathy, and social skills as predictors of different bullying roles.

\begin{tabular}{cccc}
\hline \multirow{2}{*}{ Predictors } & Victims & Bullies & Bully-Victims \\
\cline { 2 - 4 } & OR (95\% CI) & OR (95\% CI) & OR (95\% CI) \\
\hline Age & $1.04(0.89-1.21)$ & $0.98(0.74-1.30)$ & $1.22(1.06-1.41)$ \\
Male & $1.21(0.71-2.08)$ & $2.80(0.94-8.36)$ & $2.60(1.54-4.38)$ \\
Self-esteem & $0.91(0.85-0.97)$ & $1.03(0.90-1.18)$ & $0.91(0.86 \mathrm{v} 0.97)$ \\
Affective empathy & $1.10(1.01-1.19)$ & $1.10(0.94-1.29)$ & $1.03(0.96-1.11)$ \\
Cognitive empathy & $1.06(0.98-1.15)$ & $0.94(0.82-1.08)$ & $1.05(0.98-1.12)$ \\
Communicative skills & $1.03(0.99-1.07)$ & $1(0.93-1.06)$ & $0.99(0.96-1.02)$ \\
Assertiveness & $0.93(0.86-1)$ & $1.25(1.04-1.50)$ & $0.90(0.84-0.97)$ \\
Conflict resolution & $0.96(0.90-1.02)$ & $0.92(0.82-1.02)$ & $1.02(0.96-1.08)$ \\
\hline
\end{tabular}

Note: All comparisons were made using the uninvolved as a reference category.

Table 4 shows the results of multinomial regression analysis including age, gender, self-esteem, empathy, and social skills as predictors of different cyberbullying roles (Nagelkerke $\mathrm{R}^{2}=0.13$ ). The variables that uniquely predicted being a cybervictim were being older and having higher cognitive empathy. Cyberbullies reported higher affective empathy. The role of the cyberbully-victim was predicted by being older, male, having low self-esteem, and having higher affective empathy.

Table 4. Multinomial regression with age, gender, self-esteem, empathy, and social skills as predictors of different cyberbullying roles.

\begin{tabular}{cccc}
\hline \multirow{2}{*}{ Predictors } & Cybervictims & Cyberbullies & Cyberbully-Victims \\
\cline { 2 - 4 } & OR (95\% CI) & OR (95\% CI) & OR (95\% CI) \\
\hline Age & $1.27(1.06-1.52)$ & $1.25(0.96-1.63)$ & $1.19(1.01-1.40)$ \\
Male & $0.79(0.41-1.49)$ & $2.12(0.76-5.91)$ & $1.85(1.01-3.39)$ \\
Self-esteem & $0.97(0.89-1.04)$ & $0.96(0.85-1.08)$ & $0.93(0.86-.99)$ \\
Affective empathy & $0.92(0.84-1.01)$ & $1.22(1.04-1.44)$ & $1.11(1.01-1.22)$ \\
Cognitive empathy & $1.11(1.02-1.21)$ & $0.95(0.83-1.09)$ & $1(0.92-1.09)$ \\
Social skills & $0.99(0.95-1.03)$ & $0.98(0.92-1.05)$ & $0.99(0.95-1.03)$ \\
Assertiveness & $1.04(0.95-1.15)$ & $0.93(0.81-1.07)$ & $0.94(0.86-1.02)$ \\
Conflict resolution & $0.98(0.91-1.05)$ & $0.94(0.84-1.05)$ & $1.02(0.95-1.09)$ \\
\hline
\end{tabular}

Note: All comparisons were made using the uninvolved group as a reference category. 


\section{Discussion}

One of the most researched interpersonal violent phenomena occurring in childhood and adolescence are bullying and cyberbullying, as these types of violence have serious short- and long-term consequences. A literature review showed that most of the studies about bullying and cyberbullying have been conducted in wealthy, Western countries [1]. Nevertheless, knowledge about violence, including associated risk and protective factors, is needed the most in disadvantaged areas, including many regions of Latin America [2,3,13-15]. This knowledge can only be gathered using validated measurement tools. The current study uncovered good psychometric properties of the European questionnaires EIBP-Q and ECIP-Q [61-63], when used to measure bullying and cyberbullying in Peru. These instruments were also found to have good psychometric properties for other Latin American countries, such as Colombia [16,17] and Ecuador [3]. Thus, bullying and cyberbullying seem to have similar characteristics and factor structures in different geographical areas, including certain understudied regions, such as rainforests.

Scientific evidence from this study showed that both the EBIP-Q and ECIP-Q can be used to measure bullying and cyberbullying in the Peruvian Amazonia. This region is one of the most economically depressed and educationally disadvantaged in Peru. Thus, both questionnaires can be very useful to detect and help eradicate bullying and cyberbullying among Peruvian adolescents. Having these instruments available also broadens horizons for research focused on bullying and cyberbullying in Peru. Based on the current results, it will also be possible to conduct cross-national and transcultural comparative studies in different countries, including Peru, Colombia, and Ecuador, as well as other more distant European countries.

There is a wide variety of ways to define and measure bullying and cyberbullying [61,62]. For this reason, comparing their prevalence rates across different countries is still a scientific challenge. The results of this study-obtained based on definitions, methods, and instruments that had been broadly used and validated in other countries-contribute to the advancement of this research line.

This study showed that $4.5 \%$ of students reported bullying perpetration, $24.2 \%$ reported being victims, and $28.7 \%$ reported being bully-victims. As a whole, the percentage of victims was similar to the one found by Fleming and Jacobsen [18] in 19 countries around the world. However, the prevalence rate of students involved as bully/victims was high in comparison to many other countries [1,19]. Thus, the current study showed that, as also pointed out by previous research, school violence in some Latin American countries is higher than in European or North American countries [22]. With respect to Latin American countries, this study showed a higher prevalence rate of bullying in the Peruvian Amazonia, in comparison to the average estimated rates for Peru [15]. The results of this study showed that the prevalence rate of bullying involvement is mostly similar to those reported through surveys conducted by Peruvian government [25-28]. Given that this study reported results obtained with validated and reliable instruments, it is possible to conclude, from a transcultural and intracultural comparison, that bullying is a serious problem in the Peruvian Amazonia.

This study also found that $5.6 \%$ of participants reported cyberperpetration, $13.6 \%$ reported cybervictimization, and $17 \%$ reported being cyberbully-victims. This means that one out of three participants was involved in cyberbullying, which is more than the average cross-national prevalence rate of around one out of five [1,19]. When compared to geographically close countries, involvement rates are within the expected range, although they might be considered to be medium-high $[15,24]$. When compared to the few existent studies in Peru [30,31], involvement in cyberbullying victimization was slightly lower in the current study. Still, in contrast to other regions of Peru, the Peruvian Amazonia is a particularly economically disadvantaged area with reduced Internet access and limited access to digital devices and smartphones. Therefore, the prevalence rates of cyberbullying are particularly disturbing and prevention, and intervention programs are urgently needed.

There is a noteworthy overlap between bullying and cyberbullying. According to this study, one out of three students is involved in both problem behaviors. This finding falls in line with the results of other studies that showed that bullying and cyberbullying tend to form patterns of antisocial 
behaviors [12]. There is a relationship between victimization in face-to-face and virtual contexts. Therefore, bullying and cyberbullying prevention and intervention programs in Peru should focus on both interconnected problem behaviors. These comprehensive programs should include components related to both face-to-face behavior and cyberbehavior.

In accordance with previous scientific literature reviews, it was expected that victimization and perpetration of bullying $[38,41]$ and cyberbullying $[39,40]$ would be negatively related to self-esteem. The results of the current study confirmed these expectations, except when it came to the relationship between bullying perpetration and self-esteem. This finding differs from the conclusions of most studies around the world [36], possibly indicating a distinctive feature of adolescents in the Peruvian Amazonia. These results should be confirmed in future studies.

In the current study, bullying and cyberbullying victimization were found to be positively related to both affective and cognitive empathy. However, no relationship was found between bullying perpetration, and affective and cognitive empathy. This seems to reinforce certain researchers' theory that victims are more sensitive than others [49], since adolescents with high empathy may be able to anticipate the emotional impact that aggression has on the victim and, thus, be dissuaded from hurting others [48]. On the other hand, these findings differ from some hypotheses that present bullies as highly empathetic but, at the same time, manipulative and Machiavellian [50].

Social skills such as conflict resolution and communication were not related to bullying and cyberbullying. The results obtained in the current study, with adolescents from the Peruvian Amazonia, are not consistent with what has been observed in other studies conducted in different places around the world $[40,56,57]$. Only assertiveness was negatively related to bullying and cyberbullying perpetration, which is a similar finding to some previous studies [58]. It is possible that these social skills are not applicable in real-life situations. Therefore, specific training in social competence, and not only social skills, could be beneficial.

It was also found that low self-esteem and high affective empathy were predictors of victimization in adolescents from the Peruvian Amazonia. This is consistent with the findings of a study conducted recently in its neighboring country, Ecuador, with the same methods and instruments [3]. These findings reinforce previous findings from studies in other countries that showed high levels of empathy in victims of bullying [37,46].

Being a bullying perpetrator was predicted by high assertiveness. This contradicts other findings that showed that low social skills predicted more peer aggression [59]. It is also inconsistent with the findings of a study conducted in Ecuador [3] that showed that aggression was predicted by low self-esteem and low cognitive empathy. None of the tested social skills (communication, assertiveness, and conflict resolution) showed predictive value. Moreover, being a bully-victim was predicted by being older, male, having low self-esteem, and having low assertiveness.

Being a cybervictim was predicted by being older and having higher levels of cognitive empathy. The predictive role of empathy with respect to cybervictimization has been described previously in some studies [32], although most of the studies found high levels of affective empathy in victims [42]. There were also several research studies that did not find a significant relationship between empathy, bullying, and cyberbullying [37,40]. Being a cyberbully was predicted by a higher level of affective empathy. Being a cyberbully-victim was predicted by being older, male, having low self-esteem, and having higher levels of affective empathy. Thus, high affective empathy predicted both being a cyberbully and a cyberbully/victim, which is a rather unexpected finding. This could indicate that cyberaggression, unlike physical aggression, is associated with a profile of people who use their high affective empathy to harm and subdue their peers [50]. Future studies should be conducted to explain these results.

\section{Conclusions}

The current study provides further evidence for the predictive role of self-esteem, empathy, and social skills, in relation to bullying and cyberbullying. Thus, preventing and reducing bullying and 
cyberbullying in Peruvian adolescents requires designing and implementing education strategies that enhance self-esteem, empathy, and social skills. These strategies must be implemented throughout the school years, starting in early education, in order to boost prevention efforts. This is important, because it was found that certain bullying and cyberbullying roles were predicted by being older. Gender should also be taken into account when developing strategies, as being male is also a predictor of bullying and cyberbullying. Moreover, programs should focus on applying self-esteem, empathy, and social skills to real-life situations, not only to help students improve their social skills but also to help them develop competencies for behaving in a prosocial way.

This study had several limitations. Certain limitations were related to the research methods, namely, that the study was cross-sectional and conducted through self-reports. Although predictions were made on a theoretical basis, future longitudinal studies should confirm the results of this study while disentangling predictors from correlates and consequences. The use of peer-reports, combined with self-reports, could contribute to higher accuracy of results in future studies. The low reliability registered after the use of Rosenberg's self-esteem scale also limits the interpretation of the current findings.

More research on bullying and cyberbullying is needed, especially in more vulnerable countries with less economic development. Comparative studies involving both wealthier participants and participants from disadvantaged geographical areas could be especially interesting. Using validated instruments, such as those used in the current study, is key to allowing transcultural comparisons. Scientific evidence is particularly valuable when making adequate political decisions in education, such as designing and implementing bullying and cyberbullying prevention and intervention programs that are adapted to cultural characteristics and needs.

Author Contributions: Design of the study, A.J.R.-H.; conceptualization, A.J.R.-H., I.Z., and J.M.; methodology, A.J.R.-H., J.M., and I.Z.; analysis, I.Z.; investigation, A.J.R.-H., J.M., and I.Z.; resources, A.J.R.-H.; data collection, J.M.; writing - original draft preparation, J.M. and A.J.R.-H.; writing-review and editing, A.J.R.-H. and I.Z.; visualization, A.J.R.-H. and I.Z.; supervision, A.J.R.-H. and I.Z.; project administration, A.J.R.-H. All authors have read and agreed to the published version of the manuscript.

Funding: The Spanish National I+D+I Plan under project PSI2016-74871-R, the Cátedra de Cooperación al Desarrollo-Universidad de Córdoba (Spain), the Ayuntamiento de Córdoba (Spain), the Area de Cooperación y Solidaridad-Universidad de Córdoba (Spain).

Acknowledgments: The authors are grateful for the support from the Restinga association, and the schools and students who participated. A scholarship granted by the University of Córdoba as part of a Plan for Cooperation and Education for Development allowed this study to be conducted in Peruvian Amazonia. The authors are also thankful to the Spanish-English translator of this article, Valle Mérida (valle.trad@gmail.com).

Conflicts of Interest: The authors declare no conflict of interest.

\section{References}

1. Zych, I.; Ortega-Ruiz, R.; Del Rey, R. Scientific Research on Bullying and Cyberbullying: Where Have We Been and Where Are We Going. Aggress. Violent Behav. 2015, 24, 188-198. [CrossRef]

2. Del Rey, R.; Ortega, R. Bullying en los países pobres: Prevalencia y coexistencia con otras formas de violencia. Int. J. Psychol. Psychol. Ther. 2008, 8, 39-50.

3. Rodríguez-Hidalgo, A.J.; Pantaleón, Y.; Calmaestra, J. Psychological Predictors of Bullying in Adolescents from Pluricultural Schools: A Transnational Study in Spain and Ecuador. Front. Psychol. 2019, 10, 1383. [CrossRef]

4. Smith, P.K.; Cowie, H.; Olafsson, R.F.; Liefooghe, A.P.D. Definitions of Bullying: A Comparison of Terms Used, and Age and Gender Differences, in a Fourteen-Country International Comparison. Child. Dev. 2002, 73, 1119-1133. [CrossRef]

5. Ortega-Ruiz, R.; Avilés, J.M. Autoinforme Para La Evaluación Del Bullying; Autors: Valladolid, Spain, 2005.

6. Rodríguez, F.J.; Gutierrez, C.; Herrero, F.J.; Hernandez, E.; Carbonero, P.G.; Jimenez, A. Violencia En El Marco Escolar de La Enseñanza Obligatoria: El Profesorado Como Referencia. Aula Abierta 2002, 79, 139-152.

7. Salmivalli, C. Bullying and the Peer Group: A Review. Aggress. Violent Behav. 2010, 15, 112-120. [CrossRef] 
8. Menesini, E.; Nocentini, A.; Palladino, B.E.; Frisén, A.; Berne, S.; Ortega-Ruiz, R.; Calmaestra, J.; Scheithauer, H.; Schultze-Krumbholz, A.; Luik, P.; et al. Cyberbullying Definition Among Adolescents: A Comparison Across Six European Countries. Cyberpsychol. Behav. Soc. Netw. 2012, 15, 455-463. [CrossRef]

9. Tokunaga, R.S. Following You Home from School: A Critical Review and Synthesis of Research on Cyberbullying Victimization. Comput. Hum. Behav. 2010, 26, 277-287. [CrossRef]

10. Gámez-Guadix, M.; Borrajo, E.; Almendros, C. Risky Online Behaviors among Adolescents: Longitudinal Relations among Problematic Internet Use, Cyberbullying Perpetration, and Meeting Strangers Online. J. Behav. Addict. 2016, 5, 100-107. [CrossRef]

11. Slonje, R.; Smith, P.K.; Frisén, A. The Nature of Cyberbullying, and Strategies for Prevention. Comput. Hum. Behav. 2013, 29, 26-32. [CrossRef]

12. Nasaescu, E.; Zych, I.; Ortega-Ruiz, R.; Farrington, D.P.; Llorent, V.J. Longitudinal Patterns of Antisocial Behaviors in Early Adolescence: A Latent Class and Latent Transition Analysis. Eur. J. Psychol. Appl. Leg. Context 2020, 12, 85-92. [CrossRef]

13. Krisch, M.; Eisner, M.P.; Mikton, C.; Butnart, A. Global Strategies to Reduce Violence by $50 \%$ in 30 Years; Institute of Criminology Violence Research Centre and World Health Organization, University of Cambridge: Cambridge, UK, 2015.

14. Rodríguez-Hidalgo, A.J.; Solera, E.; Calmaestra, J. Psychological Predictors of Cyberbullying according to Ethnic-Cultural Origin in Adolescents: A National Study in Spain. J. Cross-Cult. Psychol. 2018, 49, 1506-1522.

15. Herrera-López, M.; Romera, E.M.; Ortega-Ruiz, R. Bullying y ciberbullying en Latinoamérica. Rev. Mex. Investig. Educ. 2018, 23, 125-155.

16. Herrera-López, M.; Casas, J.A.; Romera, E.M.; Ortega-Ruiz, R.; Del Rey, R. Validation of the European Cyberbullying Intervention Project Questionnaire for Colombian Adolescents. Cyberpsychol. Behav. Soc. Netw. 2017, 20, 117-125. [CrossRef]

17. Herrera-López, M.; Romera, E.; Ortega-Ruiz, R. Bullying y cyberbullying en Colombia; coocurrencia en adolescentes escolarizados. Rev. Latinoam. Psicol. 2017, 49, 163-172. [CrossRef]

18. Fleming, L.C.; Jacobsen, K.H. Bullying among Middle-School Students in Low and Middle Income Countries. Health Promot. Int. 2010, 25, 73-84. [CrossRef]

19. Modecki, K.; Minchin, J.; Harbaugh, A.; Guerra, N.; Reunions, K. Bullying Prevalence across Contexts: A Meta-Analysis Measuring Cyber and Traditional Bullying. J. Adolesc. Health 2014, 55, 602-611.

20. Brochado, S.; Soares, S.; Fraga, S. A Scoping Review on Studies of Cyberbullying Prevalence among Adolescents. Trauma Violence Abuse 2017, 18, 523-531. [CrossRef]

21. Sorrentino, A.; Baldry, A.C.; Farrington, D.P.; Blaya, C. Epidemiology of Cyberbullying across Europe: Differences between Countries and Genders. Educ. Sci. Theory Pr. 2019, 19, 74-91. [CrossRef]

22. UNICEF. Hidden in Plain Sight: A Statistical Analysis of Violence against Children; UNICEF: New York, NY, USA, 2014.

23. Eljach, S. Violencia Escolar En America Latina y El Caribe: Superficie y Fondo; UNICEF Y PLAN: Panamá City, Republica de Panamá, 2011.

24. Román, M.; Murillo, F.J. Latin America: School bullying and academic achievement. CEPAL Rev. 2011, 2011, 37-53. [CrossRef]

25. Cabra, F.; Marciales, G. Cyberbullying and Education: A review of remergent issues in Latin America research. In Cyberbullying across the Globe; Springer International Publishing: New York, NY, USA, 2016; pp. 131-147.

26. Ministerio de Salud. Encuesta Global de Salud Escolar: Resultados; MINSA: Lima, Perú, 2011.

27. MINEDU. Reporte de Casos de Violencia Escolar En El Perú; Ministerio de educación del Perú: San Borja, Peru, 2018.

28. INEI. Encuesta Nacional Sobre Relaciones Sociales (ENARES 2013-2015) Principales Resultados; Instituto Nacional de Estadística e informática: Lima, Perú, 2015.

29. Gutierrez, I.A.; Molina, O.; Nopo, H. Stand against Bullying: An Experimental School Intervention; IZA-Institute of Labor Economics: Bonn, Germany, 2018.

30. Miranda, R.; Oriol, X.; Amutio, A.; Ortúzar, H. Bullying en la adolescencia y satisfacción con la vida: Puede el apoyo de los adultos de la familia y de la escuela mitigar este efecto? Rev. Psicodidáct. 2018, 24, 39-45. [CrossRef] 
31. Miranda, R.; Oriol, X.; Amutio, A. Risk and Protective Factors at School: Reducing Bullies and Promoting Positive Bystanders' Behaviors in Adolescence. Scand. J. Psychol. 2019, 60, 106-115. [CrossRef]

32. Manzuoli, H.; Medina, C. Cyberbullying, Detección y Factores de Análisis: Un Estudio Comparativo. Rev. Espac. 2019, 40, 4 .

33. van Geel, M.; Goemans, A.; Zwaanswijk, W.; Gini, G.; Vedder, P. Does Peer Victimization Predict Low Self-Esteem, or Does Low Self-Esteem Predict Peer Victimization? Meta-Analyses on Longitudinal Studies. Dev. Rev. 2018, 49, 31-40. [CrossRef]

34. Kowalski, R.M.; Limber, S.P.; McCord, A. A Developmental Approach to Cyberbullying: Prevalence and Protective Factors. Aggress. Violent Behav. 2019, 45, 20-32. [CrossRef]

35. Veenstra, R.; Lindenberg, S.; Munniksma, A.; Dijkstra, J.K. The Complex Relation between Bullying, Victimization, Acceptance, and Rejection: Giving Special Attention to Status, Affection, and Sex Differences. Child. Dev. 2010, 81, 480-486. [CrossRef]

36. Donnellan, M.B.; Trzesniewski, K.H.; Robins, R.W.; Moffitt, T.E.; Caspi, A. Low Self-Esteem Is Related to Aggression, Antisocial Behavior, and Delinquency. Psychol. Sci. 2005, 16, 328-335. [CrossRef]

37. Zych, I.; Farrington, D.P.; Ttofi, M.M. Protective Factors against Bullying and Cyberbullying: A Systematic Review of Meta-Analyses. Aggress. Violent Behav. 2019, 45, 4-19. [CrossRef]

38. Tsaousis, I. The Relationship of Self-Esteem to Bullying Perpetration and Peer Victimization among Schoolchildren and Adolescents: A Meta-Analytic Review. Aggress. Violent Behav. 2016, 31, 168-199. [CrossRef]

39. Chen, L.; Ho, S.; Lwin, M. A Meta-Analysis of Factors Predicting Cyberbullying Perpetration and Victimization: From the Social Cognitive and Media Effects Approach. New Media Soc. 2017, 19, 1194-1213. [CrossRef]

40. Kowalski, R.M.; Giumetti, G.W.; Schroeder, A.N.; Lattanner, M.R. Bullying in the digital age: A critical review and meta-analysis of cyberbullying research among youth. Psychol. Bull. 2014, 140, 1073-1137. [CrossRef]

41. Rodríguez-Hidalgo, A.J.; Ortega-Ruiz, R.; Zych, I. Peer Victimization and Ethnic-Cultural Peer Victimization: Self-Esteem and School Relations between Different Cultural Groups of Students in Andalusia, Spain // Victimización étnico-cultural entre iguales: Autoestima y relaciones en la escuela entre. Rev. Psicodidáctica 2013, 19, 191-210. [CrossRef]

42. Jolliffe, D.; Farrington, D.P. Examining the Relationship between Low Empathy and Bullying. Aggress. Behav. 2006, 32, 540-550. [CrossRef]

43. Del Rey, R.; Lazuras, L.; Casas, J.A.; Barkoukis, V.; Ortega-Ruiz, R.; Tsorbatzoudis, H. Does Empathy Predict (Cyber) Bullying Perpetration, and How Do Age, Gender and Nationality Affect This Relationship? Learn. Individ. Differ. 2016, 45, 275-281. [CrossRef]

44. Jolliffe, D.; Farrington, D.P. Development and Validation of the Basic Empathy Scale. J. Adolesc. 2006, 29, 589-611. [CrossRef]

45. Smith, P.K.; Thompson, D. Practical Approaches to Bullying; Fulton: London, UK, 1999.

46. Fousiani, K.; Dimitropoulou, P.; Michaelides, M.P.; Van Petegem, S. Perceived Parenting and Adolescent Cyber-Bullying: Examining the Intervening Role of Autonomy and Relatedness Need Satisfaction, Empathic Concern and Recognition of Humanness. J. Child. Fam. Stud. 2016, 25, 2120-2129. [CrossRef]

47. Zych, I.; Ttofi, M.M.; Farrington, D.P. Empathy and Callous-Unemotional Traits in Different Bullying Roles: A Systematic Review and Meta-Analysis. Trauma Violence Abus. 2016, 20, 3-21. [CrossRef]

48. Ortega-Ruiz, R. Agresividad Injustificada, Bullying y Violencia Escolar; Alianza: Madrid, Spain, 2010.

49. Caravita, S.C.S.; Di Blasio, P.; Salmivalli, C. Early Adolescents' Participation in Bullying: Is ToM Involved? J. Early Adolesc. 2010, 30, 138-170. [CrossRef]

50. Sutton, J.; Smith, P.K.; Swettenham, J. Social Cognition and Bullying: Social Inadequacy or Skilled Manipulation? Br. J. Dev. Psychol. 1999, 17, 435-450.

51. Oliva, A. Desarrollo Positivo Adolescente y los Activos que lo Promueven: Un Studio en Centros Docentes Andaluces; Junta de Andalucía, Secretaría General de Salud Pública y Participación: Sevilla, Spain, 2011.

52. Horne, A.M.; Socherman, R. Profile of a Bully: Who Would Do Such a Thing? Educ. Horiz. 1996, 74, 77-83.

53. Perren, S.; Alekader, F.D. Social Behavior and Peer Relationships of Victims, Bully-Victims, and Bullies in Kindergarten. J. Child. Psychol. Psychiatry 2006, 47, 45-57. [CrossRef]

54. Rupp, S.; Elliot, S.N.; Gresham, F.M. Assessing Elementary Students' Bullying and Related Social Behaviors: Cross-Informant Consistency across School and Home Environments. Child. Youth Serv. Rev. 2018, 93, 458-466. [CrossRef] 
55. Sterzing, P.R.; Shattuck, P.T.; Narendorf, S.C.; Wagner, M.; Cooper, B.P. Bullying Involvement and Autism Spectrum Disorders: Prevalence and Correlates of Bullying Involvement among Adolescents with an Autism Spectrum Disorder. Arch. Pediatr. Adolesc. Med. 2012, 166, 1058-1064. [CrossRef]

56. Cook, C.R.; Williams, K.R.; Guerra, N.G.; Kim, T.E.; Sadek, S. Predictors of Bullying and Victimization in Childhood and Adolescence: A Meta-Analytic Investigation. Sch. Psychol. Q. 2010, 25, 65-83. [CrossRef]

57. Heydenberk, R.A.; Heydenberk, W.R.; Tzenova, V. Conflict Resolution and Bully Prevention: Skills for School Success. Confl. Resolut. Q. 2006, 24, 55-69. [CrossRef]

58. Jenkins, L.N.; Demaray, M.K.; Fredrick, S.S.; Summers, K.H. Associations among Middle School Students' Bullying Roles and Social Skills. J. Sch. Violence 2014, 15, 259-278. [CrossRef]

59. Katzer, C.; Fetchenchauer, D.; Belschak, F. Cyberbullying: Who Are the Victims? A Comparison of Victimization in Internet Chatrooms and Victimization in School. J. Media Psychol. 2009, 21, 25-36. [CrossRef]

60. Bagwell, C.; Schmidt, M.E. The Friendship Quality of Overtly and Relationally Victimized Children. J. Dev. Psychol. 2011, 57, 158-185. [CrossRef]

61. Ortega-Ruiz, R.; Del Rey, R.; Casas, J.A. Evaluar el bullying y el cyberbullying validación española del EBIP-Q y del ECIP-Q. Psicol. Educ. 2016, 22, 71-79. [CrossRef]

62. Twardowska-Staszek, E.; Zych, I.; Ortega-Ruiz, R. Bullying and Cyberbullying in Polish Elementary and Middle Schools: Validation of Questionnaires and Nature of the Phenomena. Child. Youth Serv. Rev. 2018, 95, 217-225. [CrossRef]

63. Del Rey, R.; Casas, J.A.; Ortega-Ruiz, R.; Schultze-Krumbholz, A.; Scheithauer, H.; Smith, P.; Thompson, F.; Barkoukis, V.; Tsorbatzoudis, H.; Brighi, A.; et al. Structural Validation and Cross-Cultural Robustness of the European Cyberbullying Intervention Project Questionnaire. Comput. Hum. Behav. 2015, 50, 141-147. [CrossRef]

64. Viejo, C. Dating Violence y Cortejo Adolescente: Un Estudio Sobre La Violencia En Las Parejas Sentimentales de Los Jóvenes Andaluces [Dating Violence and Courting in Youths: A Study on Violence in Romantic Partners in Andalusian Youths]; Universidad de Córdoba: Córdoba, España, 2012.

65. Bentler, R.M.; Wu, E.J.C. EQS for Windows (Version 6.2) [Statistical Program for Windows]; Multivariate Software: Encino, CA, USA, 2012.

66. Hu, L.; Bentler, P.M. Cut-off Criteria for Fit Indexes in Covariance Structure Analysis: Conventional Criteria versus New Alternatives. Struct. Equ. Model. Multidiscip. J. 1999, 6, 1-55.

67. Lorenzo-Seva, U.; Ferrando, P.J. FACTOR 10; Universitat Rovira I Virgili: Murcia, Spain, 2015.

68. IBM. IBM SPSS Statistics for Windows; (Version 24); IBM Corp.: New York, NY, USA, 2011. 